Article

\title{
The Structure and Nephroprotective Activity of Oligo-Porphyran on Glycerol-Induced Acute Renal Failure in Rats
}

\author{
Jing Wang ${ }^{1,2}$, Yun Hou ${ }^{1,3}$, Delin Duan ${ }^{1,2,4}$ and Quanbin Zhang ${ }^{1,2, *}$ \\ 1 Key Laboratory of Experimental Marine Biology, Institute of Oceanology, Chinese Academy of Sciences, \\ Qingdao 266071, Shandong, China; jingwang@qdio.ac.cn (J.W.); houyun.china@gmail.com (Y.H.); \\ dlduan@qdio.ac.cn (D.D.) \\ 2 Laboratory for Marine Biology and Biotechnology, Qingdao National Laboratory for Marine Science and \\ Technology, Qingdao 266071, China \\ 3 Graduate University of the Chinese Academy of Sciences, Beijing 100049, China \\ 4 State Key Lab of Seaweed Bioactive Substances, Qingdao 266500, China \\ * Correspondence: qbzhang@qdio.ac.cn; Tel.: +86-532-8289-8708
}

Academic Editor: Keith B. Glaser

Received: 1 February 2017; Accepted: 4 May 2017; Published: 9 May 2017

\begin{abstract}
Porphyran is a sulfate galactan in the cell wall of Porphyra. Its acid hydrolysis product, oligo-porphyran (OP), was prepared and the structure studied by electrospray ionization time-of-flight mass spectrometry (ESI-TOF-MS). This oligosaccharide was mainly composed of monosulfate-oligo-galactan, disufate-oligo-galactan, trisulfate-oligo-galactan, trisulfate oligo-methyl-galactan, and 3,6-anhydrogalactose with the degree of polymerization ranging from 1 to 8 . The effects of OP were investigated in the glycerol-induced acute renal failure (ARF) model. Compared with the normal group, rats from the glycerol-induced group exhibited collecting duct and medullary ascending limb dilation and casts. The OP-treated group exerted a protective effect against glycerol-induced changes. The results showed that the administration of OP markedly decreased mortality in female ARF rats. For male ARF rats, all of which survived, OP significantly decreased the blood urea nitrogen and serum creatinine levels. Ion levels in plasma and urine were significantly changed in ARF rats, whereas OP treatment almost recovered ion levels back to normal. This study showed a noticeable renal morphologic and functional protection by OP in glycerol-induced ARF rats.
\end{abstract}

Keywords: sulfated galactan; oligo-porphyran; acute renal failure; gender difference

\section{Introduction}

Acute renal failure (ARF) is a syndrome characterized by a rapid loss of kidney function [1]. During ARF, tubular fluid flow rate and glomerular filtration rate decrease rapidly. Subsequently, the kidney is unable to produce sufficient amounts of urine, and nitrogen-containing waste substances accumulate in the blood [2-4]. ARF is a contributor to many other diseases, including cardiovascular diseases, hypertension, and diabetes mellitus [5]. This syndrome has a major impact on the life quality of patients, and it is even life-threatening in some conditions [6].

Porphyran, with a linear backbone of alternating 3-linked $\beta$-D-galactose and 4-linked $\alpha$-L-galactose-6-sulfate or 3,6-anhydro- $\alpha$-L-galactose (3,6-AG) units [7], is the main polysaccharide in the cell wall of Porphyra. Porphyran has various biological activities, which are mainly attributed to its sulfated group [8,9]. In our previous study, we found that the sulfated polysaccharides from Laminaria and its hydrolysis products had protective effect on the rats with renal impairment $[10,11]$. One of an important factor for glycerol-induced renal injury is oxidative stress [12-14]. Porphyran has been proven to have strong antioxidant activity in vitro, however, few people studied its inhibition 
effect on ARF. Glycerol was a common agent for the induction of ARF in vivo and can lead to renal oxidative stress, as previously reported [15]. Therefore, the protective effect on glycerol-induced ARF of porphyan is obvious.

Researchers found many factors of sulfated polysaccharides, such as molecular weight, degree of sulfation, and type of sugar, that influence their antioxidant activity. The earlier studies in our laboratory showed that different molecular weights of porphyan could influence the antioxidant activity [16]. Lower molecular weight porphyan exhibited stronger antioxidant activity compared with native porphyan. In this paper, we prepared oligo-porphyran by acid hydrolysis and evaluated the structure and effect of oligo-porphyran on the glycerol-induced ARF in rats. Dexamethasone was used in the positive control group due to its anti-inflammatory and antioxidant property in ARF rats [6]. The levels of blood urea nitrogen (BUN), serum creatinine (SCR), and ions in the rats' blood and urine were investigated. The aim of this study was to clarify the structure and nephroprotective activity of oligo-porphyran on glycerol-induced acute renal failure in rats.

\section{Results}

\subsection{The Structure Study of Oligo-Porphran}

\subsubsection{Preparation, Fraction, and Analysis of Oligo-Porphyran (OP)}

The chemical composition of the oligo-porphyran (OP) used in this study was shown in Table 1. It contains $71.39 \%$ galactose, $7.05 \%$ 3,6-anhydrogalactose, and $18.32 \%$ sulfate groups. Its average molecular weight was $1431 \mathrm{Da}$. This oligosaccharide was mainly composed of sulfated galactan with the degree of polymerization ranging from 1 to 8 .

Table 1. The chemical analysis of OP.

\begin{tabular}{ccccc}
\hline Sample & Mw (Kda) & Sulfate Group (\%) & Galactose (\%) & 3,6-anhydrogalactose (\%) \\
\hline OP & 1.43 & $16.90 \pm 0.51$ & $59.93 \pm 1.44$ & $6.45 \pm 0.17$ \\
\hline
\end{tabular}

The eluting profile of chromatography of OP was shown in Figure 1. Three fractions were obtained: F1, F2, and F3 from 0 to $0.3 \mathrm{M} \mathrm{NaCl}$ elutions from column chromatography, and the F4 fraction was obtained from a $0.5 \mathrm{M} \mathrm{NaCl}$ elution. The sulfate group of F1-F4 was $16.54 \%, 16.06 \%$, $18.98 \%$, and $23.18 \%$, respectively.

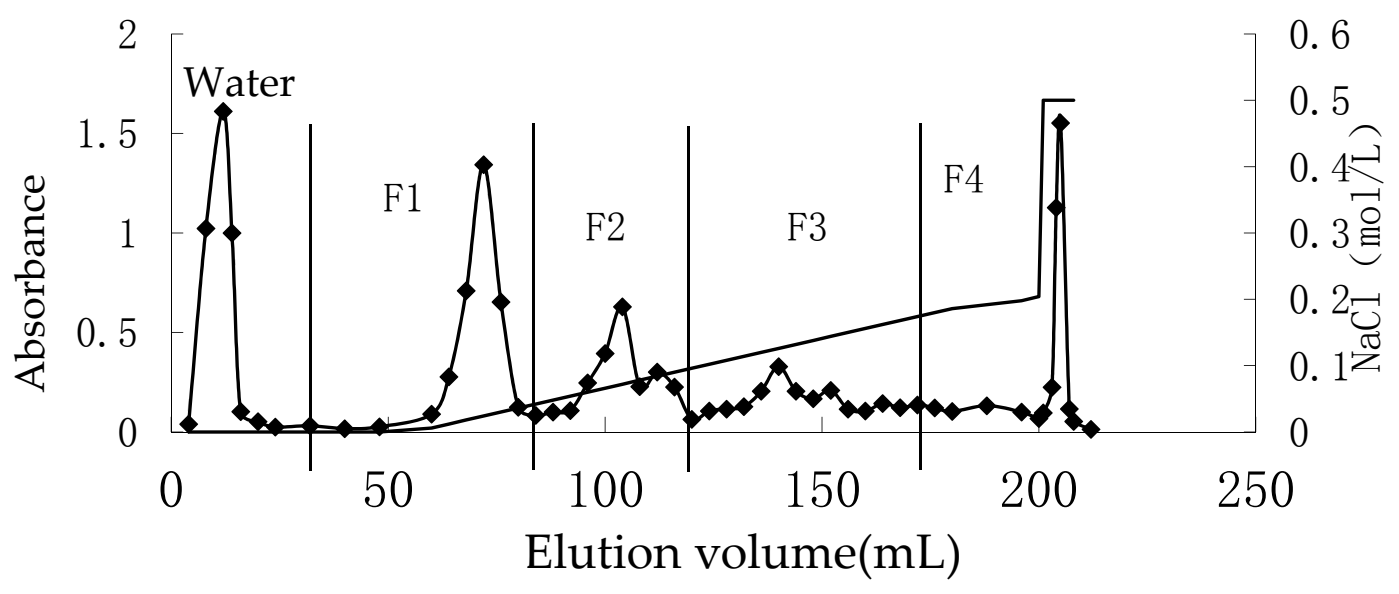

Figure 1. Chromatography of eluted OP on DEAE-sepharose CL-6B chromatography. 


\subsubsection{Structure of Oligo-Porphyran (OP)}

The degree of polymerization (DP) of OP and its fractions F1-F4 was tested by HPLC (Figure 2). The number of sulfate groups and DPs of OP increased from F1 to F4. The sulfate group numbers of F1 F4 were 1, 2, 3, and $>3$, respectively, while the DPs of their main components were 2-4, 4-6, 6-8, and $7-13$, respectively.
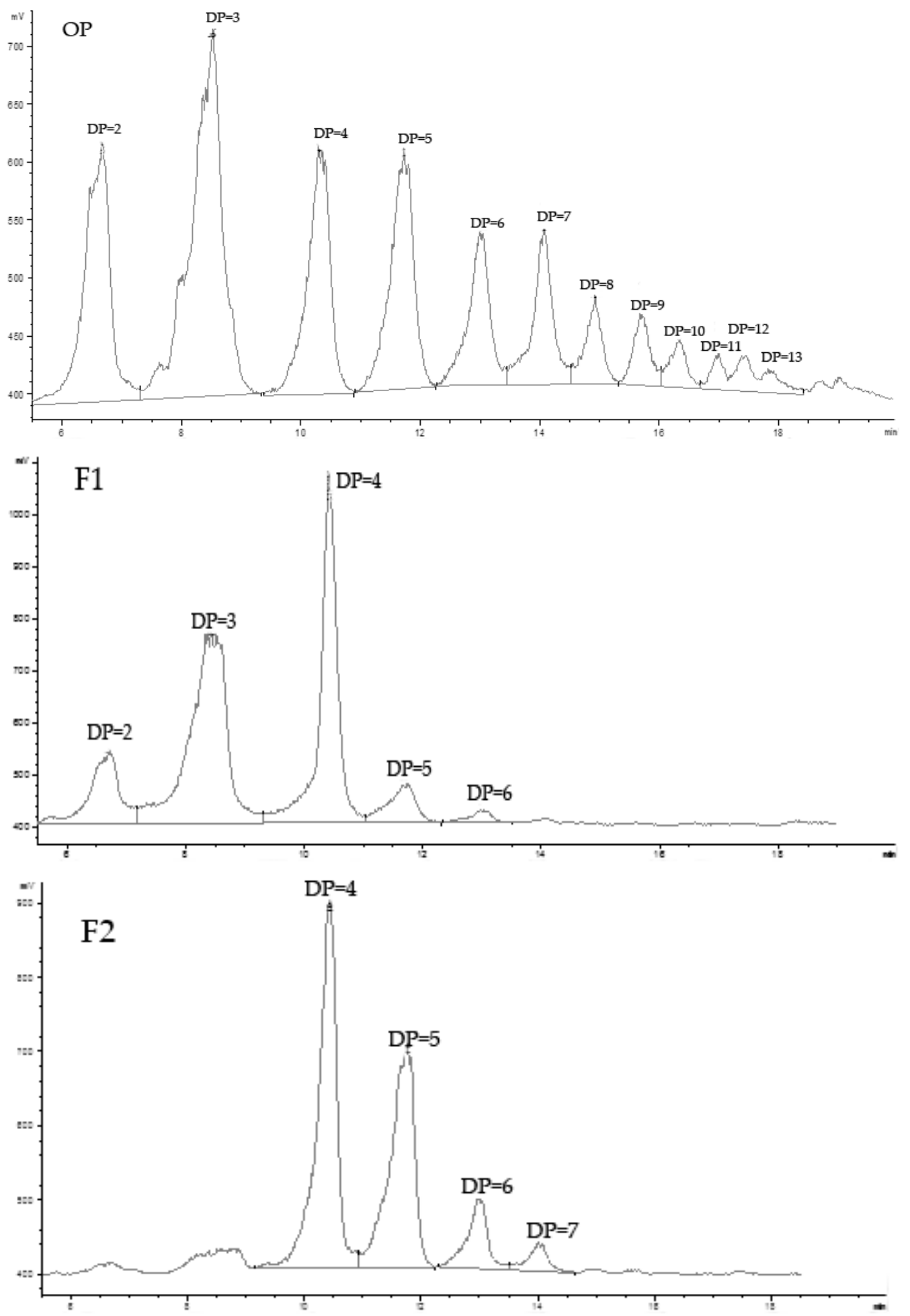

Figure 2. Cont. 

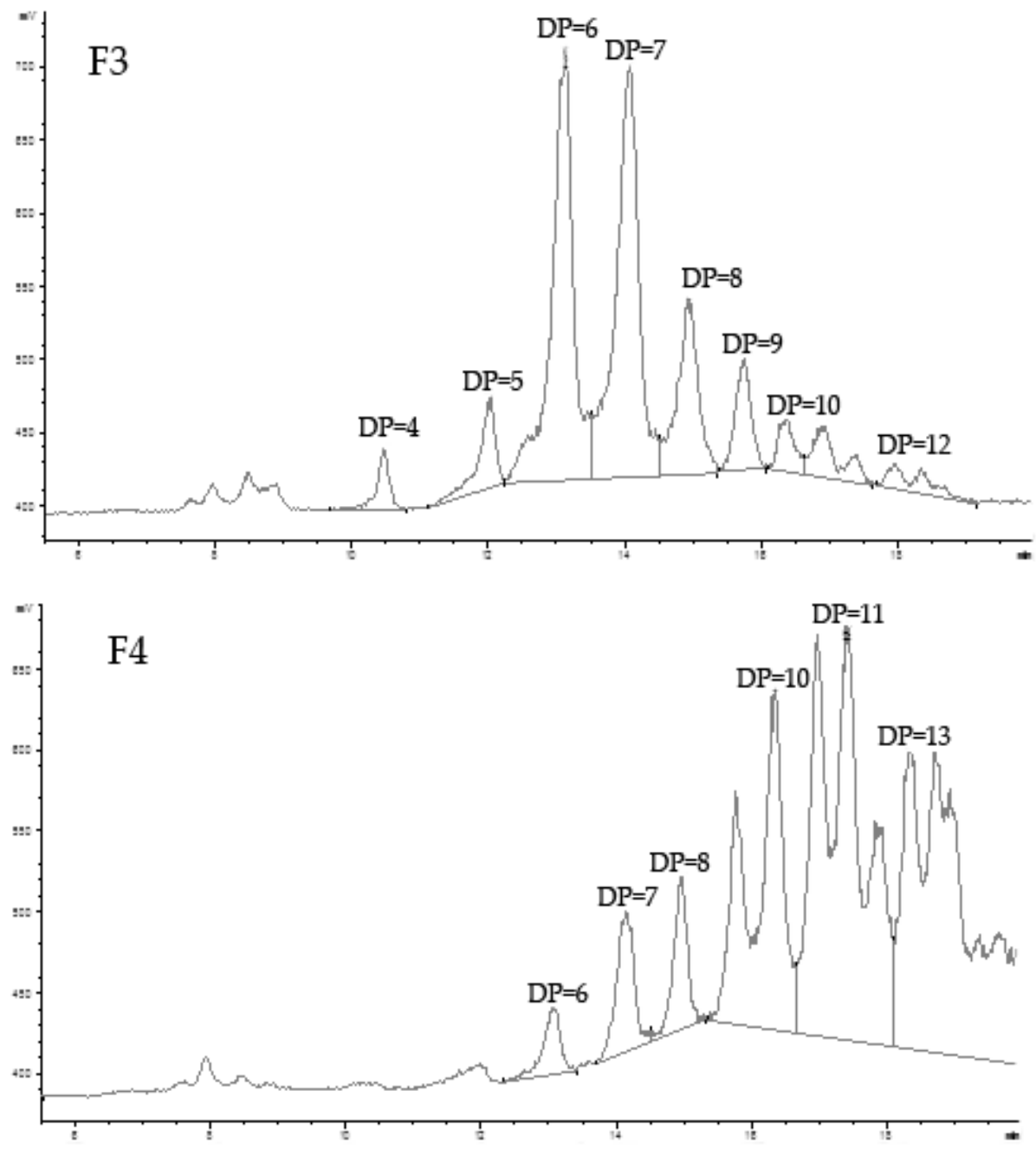

Figure 2. The degree of polymerization of OP and its fractions tested by HPLC.

We studied the molecular weight distribution and structure of F1-F4 using ESI-TOF-MS (Figure 3). From the MS-spectrum of $\mathrm{F} 1$, we found a distribution of singly-charged ions corresponding to $\left[\mathrm{Gal}_{n}-\mathrm{SO}_{3} \mathrm{H}-\mathrm{H}\right]^{-}(n=2-6)$. There were less intensive signals, which were found to be $\left[3,6-\mathrm{AG}_{-} \mathrm{Gal}_{n}-\mathrm{SO}_{3} \mathrm{H}-\mathrm{H}\right]^{-}(n=3-4)$. Analysis of the spectrum of F2 found a distribution of doubly-charged ions corresponding to $\left[\mathrm{Gal}_{n}-\left(\mathrm{SO}_{3} \mathrm{H}\right)_{2}-2 \mathrm{H}\right]^{2-}(n=3-7)$, which means $\mathrm{F} 2$ was mainly made of disulfate-oligo-galactan. A distribution of trivalently-charged ions corresponding to $\left[\mathrm{Gal}_{n}-\left(\mathrm{SO}_{3} \mathrm{H}\right)_{3}-3 \mathrm{H}\right]^{3-}(n=5-9)$ were found in the MS spectrum of F3. Three ions at $m / z 467.75(-3)$, $565.11(-3)$ and $625.08(-3)$ were also detected in ESI-TOF-MS spectrum of $\mathrm{F} 3$, suggesting the presence of $\left[\mathrm{CH}_{3}-\mathrm{Gal}_{7}-\left(\mathrm{SO}_{3} \mathrm{H}\right)_{3}-3 \mathrm{H}\right]^{3-}$, $\left[3,6-\mathrm{AG}-\mathrm{Gal}_{8}-\left(\mathrm{SO}_{3} \mathrm{H}\right)_{3}-3 \mathrm{H}\right]^{3-}$, and $\left[\mathrm{NaSO}_{3}-\mathrm{Gal}_{6}-\left(\mathrm{SO}_{3} \mathrm{H}\right)_{2}-2 \mathrm{H}\right]^{2-}$. The molecular weight distribution and structure of $\mathrm{F} 4$ was complicated; the main ions at $\mathrm{m} / \mathrm{z}$ $355.04(-3), 367.04(-4), 374.25(-5), 409.06(-6), 433.07(-7), 439.07(-5), 448.07(-4), 463.08$ $(-3), 471.48(-5)$, and $488.58(-4)$ were identified as $\left[\mathrm{Gal}_{n}\left(\mathrm{SO}_{3} \mathrm{H}\right)_{m}-\mathrm{mH}\right]^{m-}(n=5-13, m=3-7)$, while the less-intensive ions detected at $m / z 331.03(-2), 412.06(-5), 491.87(-5), 514.07(-4)$, $517.09(-3), 554.58(-4), 517.11(-3)$, and $605.09(-3)$ corresponded to $\left[\mathrm{Gal}_{3}\left(\mathrm{SO}_{3} \mathrm{H}\right)_{2}-2 \mathrm{H}\right]^{2-}$, $\left[\left(\mathrm{CH}_{3}\right)_{2}-\mathrm{Gal}_{10}-\left(\mathrm{SO}_{3} \mathrm{H}\right)_{5}-5 \mathrm{H}\right]^{5-}, \quad\left[\mathrm{NaSO}_{3}-\mathrm{Gal}_{12}-\left(\mathrm{SO}_{3} \mathrm{H}\right)_{5}-5 \mathrm{H}\right]^{5-}, \quad\left[\mathrm{NaSO}_{3}-\mathrm{Gal}_{10}-\left(\mathrm{SO}_{3} \mathrm{H}\right)_{4}-4 \mathrm{H}\right]^{4-}$, $\left[\mathrm{Gal}_{8}-\left(\mathrm{SO}_{3} \mathrm{H}\right)_{3}-3 \mathrm{H}\right]^{3-},\left[\mathrm{NaSO}_{3}-\mathrm{Gal}_{11}-\left(\mathrm{SO}_{3} \mathrm{H}\right)_{4}-4 \mathrm{H}\right]^{4-}$, and $\left[\mathrm{NaSO}_{3}-\mathrm{Gal}_{8}-\left(\mathrm{SO}_{3} \mathrm{H}\right)_{3}-3 \mathrm{H}\right]^{3-}$, respectively. 

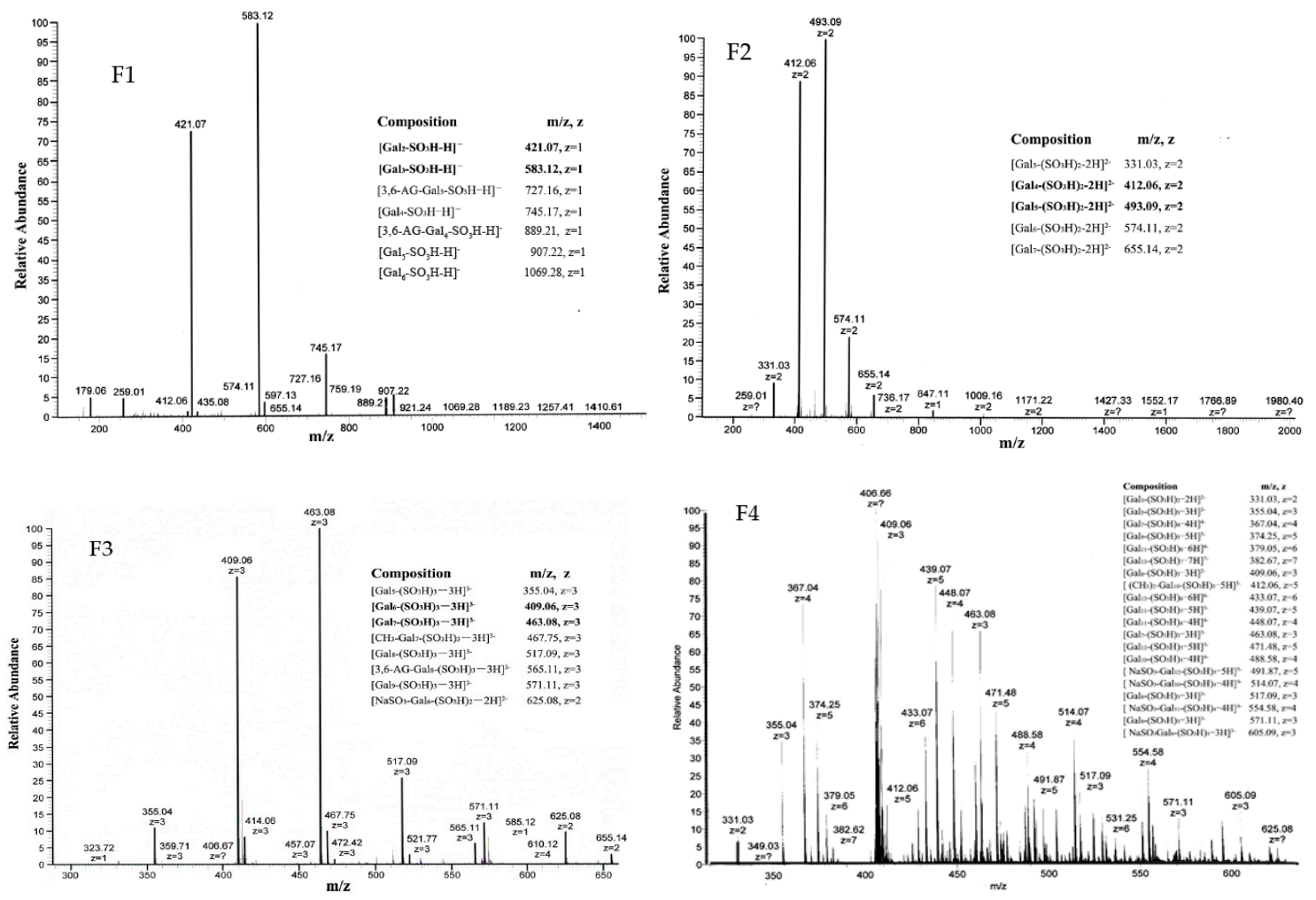

Figure 3. ESI-TOF-MS spectra of the fractions F1-F4 in a negative mode. All of the main peaks correspond to $[\mathrm{M}-n \mathrm{H}]^{n-}$ of each individual sulfated galactan oligomer.

\subsection{The Nephroprotective Activity of Oligo-Porphyran on Glycerol-Induced Acute Renal Failure in Rats}

\subsubsection{The Mortality Effect of Oligo-Porphyran (OP) in ARF Rats}

After the OP treated for seven days in ARF rats, all male rats in each group and female rats in the normal group survived, whereas deaths of female rats occurred in all ARF groups. The mortality of the negative control (NC) group was $85.71 \%$. Dexamethasone reduced the mortality slightly to $71.43 \%$. The ARF rats treated with $30 \mathrm{mg}$ oligo-porphyran per body weight (BW) per day had the lowest mortality (28.57\%), while the mortality of the OP10 group (ARF + oligo-porphyran $10 \mathrm{mg} / \mathrm{kg}$ BW per day) was $57.14 \%$ (Figure 4 ).

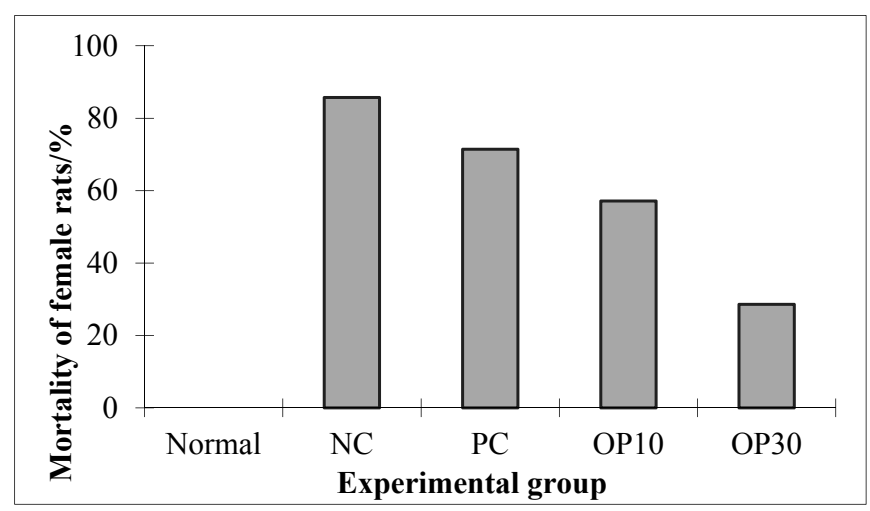

Figure 4. Mortalities of female rats in experimental groups. Normal: normal rats without acute renal failure (ARF); NC: negative control group (ARF rats); PC: positive control group (ARF + dexamethasone $0.1 \mathrm{mg} / \mathrm{kg}$ BW per day); OP10: ARF rats treated with oligo-porphyran (10 $\mathrm{mg} / \mathrm{kg}$ body weight per day); OP30: ARF rats treated with oligo-porphyran (30 mg/ $\mathrm{kg}$ body weight per day). 


\subsubsection{The BUN and SCR Level in ARF Rats}

Before glycerol injection, we tested the BUN and SCR levels in all male and female rats, the average levels of BUN and SCR were $7.64 \pm 0.71 \mathrm{nmol} / \mathrm{L}$ and $14.82 \pm 0.84 \mu \mathrm{mol} / \mathrm{L}$, respectively. Then the rats were randomly divided into five groups (seven male rats and seven female rats in each group). The rats were deprived of water for $24 \mathrm{~h}$ and received an intramuscular injection of $50 \%$ glycerol in NS into both hind limbs at a total dose of $10 \mathrm{~mL} / \mathrm{kg} \mathrm{BW}$, except for the normal group, which was injected with NS. Then the animals were allowed access to a standard diet. Before the OP injection began at $48 \mathrm{~h}$ after glycerol injection, we tested the BUN and SCR levels to see whether the ARF models were successful (Table 2). From the data showed in Table 2, we could see the levers of BUN and SCR in ARF group were much higher than in the Normal group. Thus, we concluded the ARF models were successful.

Table 2. Levels of BUN and SCR in the blood of experimental groups after injection $50 \%$ Glycerol for $48 \mathrm{~h}$.

\begin{tabular}{ccccccc}
\hline Gender & Index & Normal & NC & PC & OP10 & OP30 \\
\hline \multirow{2}{*}{ Male } & BUN $(\mathrm{nmol} / \mathrm{L})$ & $7.73 \pm 0.27$ & $11.48 \pm 1.23^{* *}$ & $12.27 \pm 0.74^{* *}$ & $11.96 \pm 1.08^{* *}$ & $12.32 \pm 2.11^{* *}$ \\
& SCR $(\mu \mathrm{mol} / \mathrm{L})$ & $15.32 \pm 0.74$ & $26.72 \pm 3.18^{* *}$ & $24.48 \pm 1.64^{* *}$ & $27.11 \pm 2.54^{* *}$ & $26.22 \pm 1.71^{* *}$ \\
\hline \multirow{2}{*}{ Female } & BUN $(\mathrm{nmol} / \mathrm{L})$ & $6.91 \pm 0.54$ & $13.44 \pm 0.88^{* *}$ & $13.18 \pm 0.68^{* *}$ & $12.64 \pm 0.67 * *$ & $14.97 \pm 1.29 * *$ \\
& & $(n=7)$ & $(n=4)$ & $(n=4)$ & $(n=5)$ & $(n=5)$ \\
& SCR $(\mu \mathrm{mol} / \mathrm{L})$ & $13.94 \pm 1.05$ & $25.64 \pm 1.94^{* *}$ & $24.99 \pm 0.96^{* *}$ & $26.70 \pm 1.27 * *$ & $26.02 \pm 1.13 * *$ \\
$(n=7)$ & $(n=4)$ & $(n=4)$ & $(n=5)$ & $(n)$ \\
\hline
\end{tabular}

\footnotetext{
Normal: normal rats without acute renal failure (ARF); NC: negative control group (ARF rats); PC: positive control group (ARF + dexamethasone $0.1 \mathrm{mg} / \mathrm{kg} \mathrm{BW}$ per day); OP10: ARF rats treated with oligo-porphyran (10 mg/kg body weight per day); OP30: ARF rats treated with oligo-porphyran (30 mg/kg body weight per day); ${ }^{* *} p<0.01$ compared with the Normal group. Statistical analysis was performed using ANOVA. Data are presented as mean \pm S.D. ( $n=7$ in male rats, $n=4-7$ in female rats).
}

As described in Figure 4, after the experiment, the mortality of the female ARF rats ranged from $28.57 \%$ to $85.71 \%$, which means most of the female ARF rats died in NC, PC, and OP10 groups. From these results we suggest that the female ARF rats may not be suitable for studying the nephroprotective activity of OP with such high mortality. Thus, in the following study, we use just the data from male ARF rats to analyze the nephroprotective activity of the OP. Figure 5A shows that the levels of BUN in the normal, dexamethasone-treated ARF and two oligo-porphyran-treated ARF groups are significantly lower than that in the NC group $(p<0.05)$. The concentrations of SCR in the oligo-porphyran-treated groups are also significantly lower than that in the NC group in Figure $5 \mathrm{~B}(p<0.01)$. Comparing the rats in OP10 and OP30 groups, both OP10 and OP30 injections could lower the BUN and SCR levels $(p<0.01$, respectively).

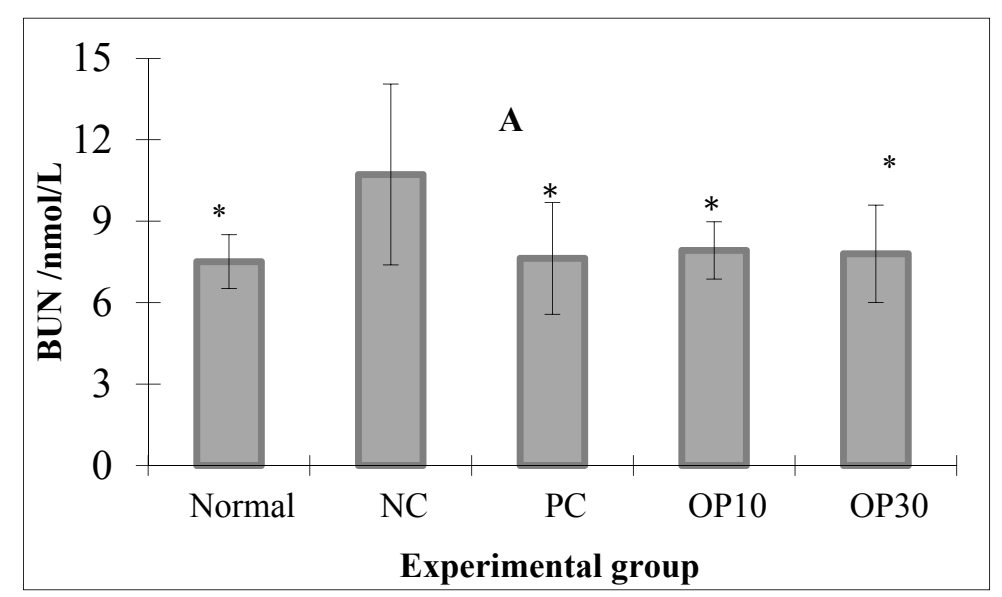

Figure 5. Cont. 


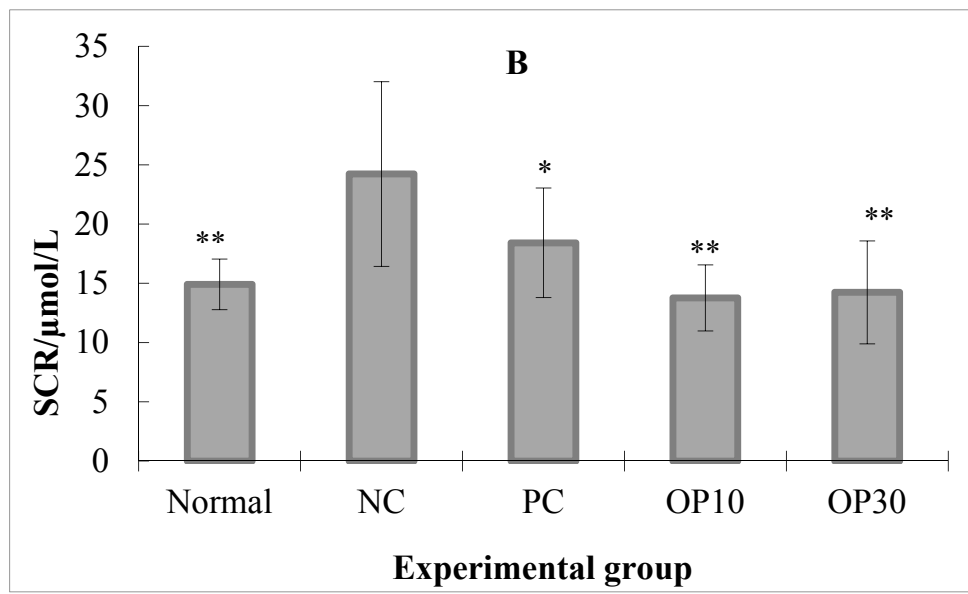

Figure 5. Blood urea nitrogen (BUN, Figure 5A) and serum creatinine (SCR, Figure 5B) levels of experimental groups. Normal: normal rats without acute renal failure (ARF); NC: negative control group (ARF rats); PC: positive control group (ARF + dexamethasone $0.1 \mathrm{mg} / \mathrm{kg}$ BW per day); OP10: ARF rats treated with oligo-porphyran (10 mg/ kg body weight per day); OP30: ARF rats treated with oligo-porphyran (30 mg/kg body weight per day); ${ }^{*} p<0.05,{ }^{* *} p<0.01$ compared with NC. Data are presented as mean \pm S.D. $(n=7)$.

\subsubsection{The Ions and Protein Levels in the Urine and Plasma of ARF Rats}

The ions and protein levels in the urine and plasma of each experimental group were analyzed (Table 3). In blood, OP treatment reduced only the concentration of $\mathrm{Cl}^{-}$significantly $(p<0.05)$. The levels of albumin and other ions, such as $\mathrm{Ca}^{2+}, \mathrm{Na}^{+}$, and $\mathrm{K}^{+}$, did not change significantly by OP, although the normal, OP10, and OP30 groups had lower concentration of $\mathrm{K}^{+}$than that of the NC group. In urine, it was noted that $\mathrm{K}^{+}, \mathrm{Na}^{+}$, and $\mathrm{Cl}^{-}$levels in the normal, OP10, and OP30 groups were significantly higher than those in the NC group $(p<0.01)$.

Table 3. Levels of protein, potassium ions, sodium ions, chlorine ions, and calcium ions in the blood (A) and urine (B) of experimental groups.

\begin{tabular}{|c|c|c|c|c|c|}
\hline $\mathbf{A}$ & & & & & \\
\hline Group & Albumin (g/L) & $\mathrm{K}^{+}(\mathrm{mmol} / \mathrm{L})$ & $\mathrm{Na}^{+}(\mathrm{mmol} / \mathrm{L})$ & $\mathrm{Cl}^{-}(\mathrm{mmol} / \mathrm{L})$ & $\mathrm{Ca}^{2+}(\mathrm{mmol} / \mathrm{L})$ \\
\hline Normal & $32.95 \pm 2.27$ & $5.48 \pm 0.63$ & $148.27 \pm 0.81 * *$ & $106.43 \pm 2.00$ ** & $2.52 \pm 0.13$ \\
\hline $\mathrm{NC}$ & $33.19 \pm 1.34$ & $6.27 \pm 2.22$ & $144.53 \pm 2.04$ & $99.41 \pm 3.84$ & $2.54 \pm 0.23$ \\
\hline PC & $36.96 \pm 1.79$ & $7.03 \pm 3.04$ & $145.68 \pm 1.98$ & $97.04 \pm 3.66$ & $2.66 \pm 0.19$ \\
\hline OP10 & $32.84 \pm 1.55$ & $5.46 \pm 0.49$ & $144.24 \pm 1.66$ & $103.70 \pm 1.99$ * & $2.49 \pm 0.10$ \\
\hline OP30 & $32.82 \pm 1.53$ & $5.12 \pm 0.24$ & $143.63 \pm 1.35$ & $103.55 \pm 0.54 *$ & $2.56 \pm 0.07$ \\
\hline \multicolumn{6}{|l|}{ B } \\
\hline Group & Albumin (g/L) & $\mathrm{K}^{+}(\mathrm{mmol} / \mathrm{L})$ & $\mathrm{Na}^{+}(\mathrm{mmol} / \mathrm{L})$ & $\mathrm{Cl}^{-}(\mathrm{mmol} / \mathrm{L})$ & $\mathrm{Ca}^{2+}(\mathrm{mmol} / \mathrm{L})$ \\
\hline Normal & $0.41 \pm 0.19$ & $64.56 \pm 10.27 *$ & $228.48 \pm 27.75^{* *}$ & $338.58 \pm 68.46^{* *}$ & $3.67 \pm 2.06$ \\
\hline NC & $0.29 \pm 0.22$ & $47.13 \pm 10.60$ & $74.07 \pm 33.67$ & $113.93 \pm 54.31$ & $5.00 \pm 2.58$ \\
\hline PC & $0.62 \pm 0.57$ & $42.88 \pm 17.50$ & $43.33 \pm 31.89 *$ & $71.49 \pm 66.48$ & $2.16 \pm 2.10 *$ \\
\hline OP10 & $0.25 \pm 0.12$ & $62.19 \pm 5.22 * *$ & $185.21 \pm 29.06^{* *}$ & $278.41 \pm 60.09 * *$ & $3.78 \pm 2.40$ \\
\hline OP30 & $0.29 \pm 0.12$ & $67.45 \pm 4.19^{* *}$ & $201.38 \pm 61.62 * *$ & $282.80 \pm 054^{* *}$ & $4.09 \pm 1.01$ \\
\hline
\end{tabular}

Normal: normal rats without acute renal failure (ARF); NC: negative control group (ARF rats); PC: positive control group (ARF + dexamethasone $0.1 \mathrm{mg} / \mathrm{kg} \mathrm{BW}$ per day); OP10: ARF rats treated with oligo-porphyran $(10 \mathrm{mg} / \mathrm{kg}$ body weight per day); OP30: ARF rats treated with oligo-porphyran $(30 \mathrm{mg} / \mathrm{kg}$ body weight per day); $p<0.05$, ** $p<0.01$ compared with NC. Statistical analysis was performed using ANOVA. Data are presented as mean \pm S.D. $(n=7)$. 


\subsubsection{Histopathological Studies on Renal Tissues of ARF Rats}

Renal tissues stained with hematoxylin and eosin were examined under light microscopy for the histopathological assay (Figure 6). The rats in the normal group were found to be in normal physiological condition. These animals had normal glomeruli with tubules (data not shown). However, the NC group rats had marked dilations in the blood capillaries of glomeruli and diffuse mononuclear infiltrations in the partial lymphocytes of glomeruli. Severe expansion and cast-shaped accumulations of dense bodies of proteinosis also appeared in the tubules (Figure 6A,B). With respect to the PC, OP10, and OP30 groups, no marked alteration was detected in the glomerulus, and normal corticomedullary demarcations were observed, although there were slight dilations in the tubules (Figure 6C,D).
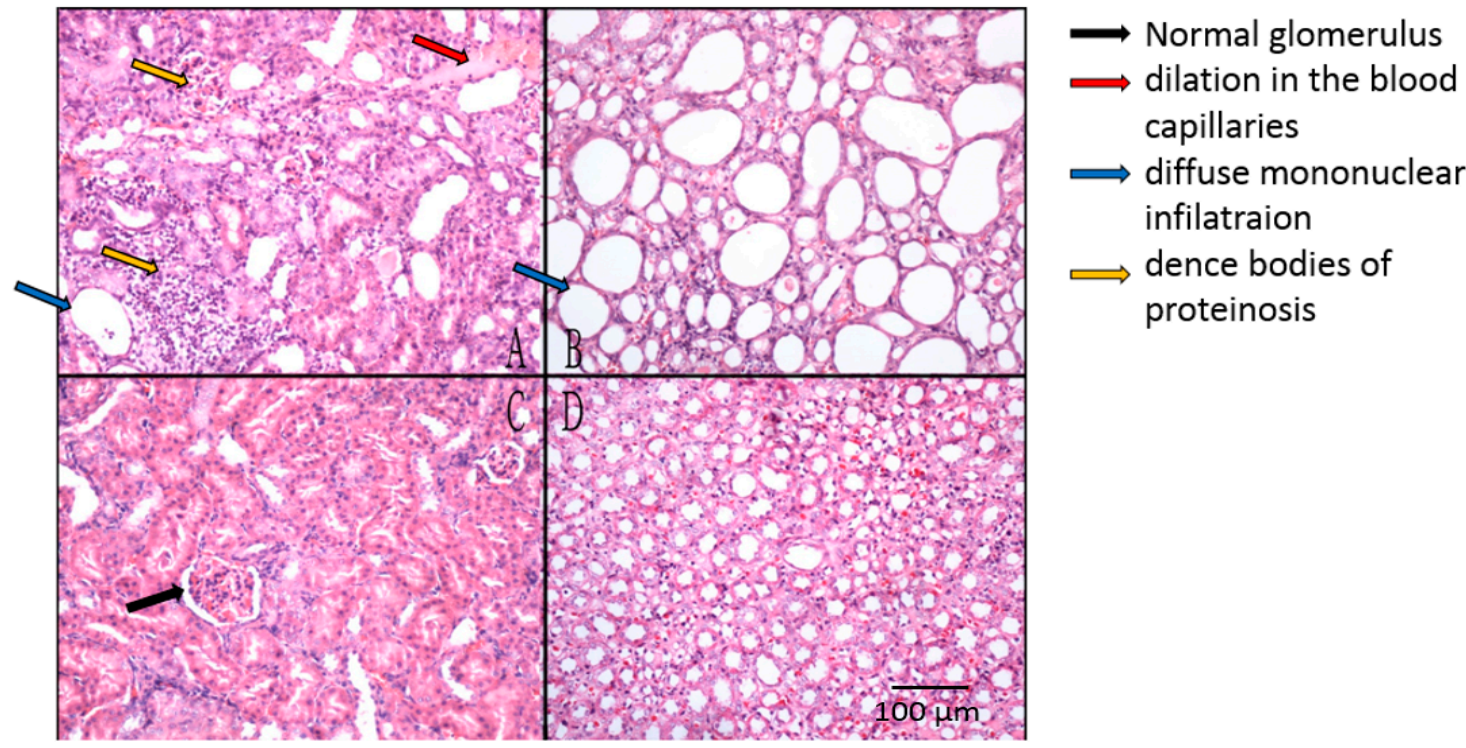

Figure 6. Histopathological studies on renal tissues of rats in the NC group (A,B) and OP10 (C,D) group. (A,C): cortex; (B,D): medulla. NC group: negative control group (acute renal failure rats); OP10 group: acute renal failure rats treated with oligo-porphyran $(10 \mathrm{mg} / \mathrm{kg}$ body weight per day).

\section{Discussion}

We got an oligo-porphyran (OP) using acid hydrolysis method from porphyran, its average molecular weight was $1431 \mathrm{Da}$. The main composition of the OP were galactose $(71.39 \%)$, 3,6-anhydrogalactose (7.05\%), and sulfate group (18.32\%), respectively. OP can be further classified using a DEAE Sepharose Fast Flow anion-exchange column and obtained four fractions (Figure 1). The degree of polymerization (DP), molecular weight distribution, and structure of F1-F4 were studied using HPLC and ESI-TOF-MS (Figures 2 and 3). The DPs of F1-F4 was increased from two to 13, in accordance with the ESI-TOF-MS results. Analysis with the ESI-TOF-MS spectrums, we found F1 was mainly made of monosulfate-oligo-galactan, F2 was mainly made of disulfate-oligo-galactan, F3 was mainly made of trisulfate-oligo-galactan, trisulfate oligo-methyl-galactan, and trisulfate 3,6-anhydrogalactose. The molecular weight distribution and structure of F4 was complicated; it was mainly made of sulfate oligo-galactan, and the sulfate groups number from three to seven. The fractions F1-F4 were all mainly made of sulfate oligo-galactan, the differences were in the number of sulfate groups. From our previous knowledge and experiments, we know the sulfate group is an important factor which could influence the antioxidant activity of sulfated polysaccharides. However, this is not to say that higher is better. Thus, in this study we chose OP for the tested samples. We should confirm if OP had nephroprotective activity in vivo, firstly. If OP exhibited excellent nephroprotective activity, we will using fractions to study the relationship between the structure and the nephroprotective activity furthermore in the future. 
Glycerol-induced renal injury in rats, which closely resembles the lesions in the human kidney with ARF caused by transfusion accidents or crush injuries [2], is the most widely used model for studying acute renal failure. Therefore, glycerol injection was employed in the present study to develop ARF rat models. The results described above indicated that glycerol-induced rats lost their renal function efficiently. Compared with the normal group, the negative control group had significantly higher BUN and SCR levels (Figure 5), and its renal tissues were in much worse physiological condition.

As mentioned above, our previous study revealed that the sulfated polysaccharides from Laminaria and its hydrolysis products had an inhibitory effect on renal impairment [10,11]. We hypothesized that low molecular weight porphyran, a sulfated galactan, could also inhibit the development of renal failure in rats, and this speculation was verified by the present study. In general, the syndrome of ARF was characterized by a rapid reduction in the ability of the kidney to eliminate waste products, such as BUN and SCR. BUN is a nitrogen-containing waste that cannot be filtrated into the urine in renal failure diseases. SCR is the product of creatine high-energy phosphate consumption [17]. They are important indicators of ARF. The reduction of SCR and BUN underscores the improvement of renal filtration function. In our experiment, OP reduced the levels of BUN and SCR in ARF rats, the activity were similar, or better, than the PC group. This means OP treatment could be notably ameliorated by the impairment of renal filtration function. We also observed significant changes of electrolyte levels in serum and urine for the rats with ARF. However, the concentrations of $\mathrm{K}^{+}, \mathrm{Na}^{+}$, and $\mathrm{Cl}^{-}$in the urine of the OP-treated groups were statistically higher than that in the NC group. According to this result, we can also conclude that the renal failure could be ameliorated by OP and the low concentration dose group exhibited excellent protection of renal function. Finally, we analyzed the renal histopathology of all of the rats, and the results demonstrated that OP reduced the lesion of kidneys compared with the NC group. Collectively, these results suggest that OP has a protective effect against glycerol-induced ARF.

However, in this experiment, we only analyzed the renal function index at the sixth experimental day. From our results we obtained that the OP treatment has a positive effect on ARF rats, however, we still did not know on which day OP treatment had exhibited the renal protective effect because of a lack of data regarding the day-by-day observation. As for the findings in the histopathological study, we need to provide additional data from further study, which could indicate that the OP treatment cures the damaged tissues day by day.

The fact that OP relieves glycerol-induced ARF might be due to the antioxidant activities of this sulfated saccharide. Many studies revealed that free radicals were critical mediators of heme-induced renal tubular damage and that antioxidants could be used to protect against renal failure $[17,18]$. Our previous report demonstrated that OP derived from Porphyra was an antioxidant, which had an inhibitory effect on superoxide, hydroxyl radicals, and hydrogen peroxide [16]. Therefore, the antioxidant activities of oligo-porphyran might contribute to its protective effect against ARF.

In this study, we also obtained an interesting result: the gender of rats affected their tolerance to the glycerol-induced ARF. Differing mortalities suggest that female rats were more sensitive to glycerol than male rats. The gender differences had been documented in the studies of other ARF models. For instance, female rats were more refractory to ischemic ARF than male rats [19], whereas female rats appeared more sensitive to cisplatin-induced ARF [20]. According to these studies, the sex hormone was considered an important reason for this difference. Our results indicated that OP reduced the mortality of female rats effectively (Figure 4). The mechanism of the differential mortality of the different sexes is still not clear, which will be the focus of future studies.

\section{Materials and Methods}

\subsection{Preparation and Analysis of Oligo-Porphyran}

Porphyran used for hydrolysis was extracted from Porphyra yezoensis, which was collected from Lianyungang $\left(35^{\circ} 01^{\prime} \mathrm{N}, 119^{\circ} 15^{\prime} \mathrm{E}\right)$, China in 2015 [21]. For the preparation of oligo-porphyran, 
porphyran was dissolved in $0.5 \mathrm{~mol} / \mathrm{L} \mathrm{H}_{2} \mathrm{SO}_{4}$ and incubated for $2 \mathrm{~h}$ at $80^{\circ} \mathrm{C}$. After the acid hydrolysis, $\mathrm{BaCl}_{2}$ was added to neutralize the solution to $\mathrm{pH}$ 7.0. The solution was centrifuged, and then the supernatant was concentrated and lyophilized to obtain oligo-porphyran [22]. Oligo-porphyran was dissolved in normal saline (NS) for animal treatment.

The chemical characteristics of oligo-porphyran were investigated. Its total sugar content was analyzed with the phenol-sulphuric acid method [23]. The monosaccharide composition [24] and the molecular weight [22] of oligo-porphyran were determined by high-performance liquid chromatography. 3,6-anhydrogalactose content was analyzed according to the method of Yaphe [25]. Sulfate group content was determined using barium chloride-gelatin method [26]. The MWs of OP was determined by high-performance gel permeation chromatography with a TSK G3000PWxl column (TOSOH Co. Ltd., Tokyo, Japan). The mobile phase was $0.2 \mathrm{M} \mathrm{Na}_{2} \mathrm{SO}_{4}$ aqueous solution, and the flow rate was $0.5 \mathrm{~mL} \mathrm{~min}{ }^{-1}$. The column temperature was maintained at $40{ }^{\circ} \mathrm{C}$, and the samples were detected with a refractive index detector (Shimadzu RID-10A). We used dextran standards with molecular weights of $2.5 \mathrm{KDa}, 7.8 \mathrm{KDa}, 12.2 \mathrm{KDa}, 21.4 \mathrm{KDa}, 41.1 \mathrm{KDa}, 84.4 \mathrm{KDa}, 133.8 \mathrm{KDa}$, and 2000 $\mathrm{KDa}$ as standards. The dextran standards dissolved in $0.2 \mathrm{M} \mathrm{Na}_{2} \mathrm{SO}_{4}$ aqueous solution to form a $1 \%$ solution and added $20 \mu \mathrm{L}$ each time. We used the molecular weight and the retention time to make the standard curve. The OP samples were analyzed using this standard curve. All data were recorded and processed using Shimadzu LC-Solution software [22].

\subsection{Fraction of Oligo-Porphyran OP}

$0.5 \mathrm{~g}$ OP was dissolved in $2 \mathrm{~mL}$ water and then filtered through a microporous membrane $(0.45 \mu \mathrm{m})$ before injecting into a DEAE Sepharose Fast Flow anion-exchange column $(2.8 \times 40 \mathrm{~cm})$. The glass column $(2.8 \times 40 \mathrm{~cm})$ was bought from Huideyi Company (Beijing, China) and DEAE Sepharose Fast Flow gel from GE Company (Boston, MA, USA), and then the column was filled with DEAE Sepharose Fast Flow by ourselves. Following loading of the sample, the column was pre-equilibrated with distilled water and then eluted by $\mathrm{NaCl}$ solution, gradiently, from 0 to $0.3 \mathrm{M}$ at a flow rate of $1.5 \mathrm{~mL} \mathrm{~min}^{-1}$. Then eluted by $0.5 \mathrm{M} \mathrm{NaCl}$ solution. The elution was monitored by the concentration of total sugar by the phenol-sulfuric acid method at $490 \mathrm{~nm}$ [23], and pooled into four fractions (F1-F4) as illustrated in Figure 1. A Sephadex G10 column (GE Company, Boston, MA, USA) was then used to desalinize the four fractions.

\subsection{The Structural Analysis of Oligo-Porphyran}

The degree of polymerization of OP, and its fractions F1-F4, was tested by HPLC [27]. A Mal-CF column was bought from the Dalian Institute of Chemical Physics (CAS, DaLian, China), and a silica-maltose and evaporative light-scattering detector were used. Chromatographic conditions were as follows: oven temperature, $30^{\circ} \mathrm{C}$; sample concentration, $10 \mathrm{mg} / \mathrm{mL}$; sample volume, $10 \mu \mathrm{L}$; mobile phase buffer, $100 \mathrm{mmol} / \mathrm{L}$ ammonium formate-formic acid ( $\mathrm{pH} 3.1)$; flow rate, $1 \mathrm{~mL} / \mathrm{min}$; and the elution conditions were as shown in Table 4.

Table 4. Mobile phase gradient.

\begin{tabular}{ccc}
\hline Time (min) & Acetonitrile (\%) & Buffer (\%) \\
\hline 0 & 80 & 20 \\
30 & 40 & 60 \\
40 & 10 & 90 \\
\hline
\end{tabular}

MW distributions of F1-F4 were determined by MS analysis with an LTQ Orbitrap XL mass spectrometer (Thermo Scientific, Sparta, NJ, USA). 


\subsection{Experimental Animals and Treatments}

$\mathrm{SD}$ rats were reared in standard conditions of humidity $(50 \pm 5 \%)$, temperature $\left(22 \pm 1^{\circ} \mathrm{C}\right)$, and lighting (12 h light/day). The animals were allowed access to a standard diet containing $20 \%$ protein and water ad libitum during the experiments. In this study, all drugs were injected into the abdominal cavity at a dose of $5 \mathrm{~mL} / \mathrm{kg}$ body weight (BW) per day. These experiments were conducted in accordance with the National Guide for the Care and Use of Laboratory Animals of China.

The rats were deprived of water for $24 \mathrm{~h}$ and received an intramuscular injection of $50 \%$ glycerol in NS into both hind limbs at a total dose of $10 \mathrm{~mL} / \mathrm{kg}$ BW. Then the animals were allowed access to a standard diet. The following experiments began at $48 \mathrm{~h}$ after glycerol injection, when the ARF models were stable.

The rats were randomly divided into five groups (seven male rats and seven female rats in each group): a normal group, an ARF group as a negative control (NC), a positive control group (PC, ARF + dexamethasone $0.1 \mathrm{mg} / \mathrm{kg}$ BW per day), an OP10 group (ARF + oligo-porphyran $10 \mathrm{mg} / \mathrm{kg} \mathrm{BW}$ per day), and an OP30 group (ARF + oligo-porphyran $30 \mathrm{mg} / \mathrm{kg}$ BW per day). All of these groups were administered by intraperitoneal injection with the samples at the dosages described above for six days, while the rats in the NC and normal groups were treated with the same volume of saline. Urine specimens were collected on the fifth and sixth experimental days. After urine sampling, the rats were anaesthetized with chloral hydrate at the dose of $10 \mathrm{mg} / \mathrm{kg}$ and killed after blood samples were taken from their hearts. The blood was centrifuged at $2250 \times \mathrm{g}$ for $20 \mathrm{~min}$ at $4{ }^{\circ} \mathrm{C}$ to obtain plasma for the biochemical analysis. The kidneys were taken and fixed in $10 \%$ formalin.

\subsection{Biological Measurement}

The urinary and plasma protein was measured by using a Pierce Coomassie Protein Assay Kit (Thermo Fisher Scientific, Petaluma, CA, USA) [28]. The principle is that, when mixed with a protein solution, the acidic coomassie-dye reagent changes color from brown to blue in proportion the amount of protein present in the sample. We used $20 \mu \mathrm{L}$ urine and blood, each extracted from rats, to test levels of ions, SCR, and BUN with an automated biochemical analyzer (CX5, Beckman Instruments, Brea, CA, USA). The ion selective electrodes (Beckman, Brea, CA, USA) was used to measure ions, such as $\mathrm{Na}^{+}$, $\mathrm{K}^{+}, \mathrm{Ca}^{2+}$, and $\mathrm{Cl}^{-}$. We used the 10-300 $\mathrm{mM} \mathrm{NaCl}, 10-100 \mathrm{mM} \mathrm{KCl}$, and 1-10 $\mathrm{mM} \mathrm{CaCl}_{2}$ as standard sfor $\mathrm{Na}^{+}, \mathrm{K}^{+}$, and $\mathrm{Ca}^{2+}$, respectively. We used 10-400 $\mathrm{mM} \mathrm{NaCl}$ as the standard for $\mathrm{Cl}^{-}$. An ISE is a sensor that determines the concentration of ions in a solution by measuring the current flow through an ion-selective membrane. The renal histopathology was investigated using the previous method [5].

\subsection{Statistical Analysis}

The Student's $t$-test was used to determine the level of significance of differences between the NC group and the other experimental groups. A significant difference was accepted with $p<0.05$.

\section{Conclusions}

This study revealed the fractions F1-F4 were all mainly made of sulfate oligo-galactan with the degree of polymerization ranging from 1 to 8 and the sulfated groups numbering $1-3$. We also found the protective effect of OP against glycerol-induced ARF. OP improved the renal functions of ARF rats markedly, as shown by renal histology and lower levels of SCR and BUN. A higher survival rate of male rats suggests a gender-related dependency of the sensitivity of rats to glycerol-induced ARF. This initial study of the OP-treated ARF did not clarify the mechanism of oligo-porphyran's protective effect and the gender differences in this ARF model, which will be the subject of future work.

Acknowledgments: This study was supported by the Science and Technology Project of Shandong province (no. 2016GSF115031, 2014GHY115017), Jiangsu Science and Techoogy Program (BE2015335), the Jiangsu Innovation Entrepreneurs Talent Program, Youth Innovation Promotion Association of CAS, under grant no. 2016190, the Natural Science Foundation of China (NSFC) (41376166), and the Special Fund for Marine Scientific Research in the Public Interest (201405040). 
Author Contributions: Jing Wang and Yun Hou conceived and designed the experiments, designed the study, provided most of the data, and wrote the article; Delin Duan helped revise the English language aspect; and Quanbin Zhang co-designed the study.

Conflicts of Interest: The authors declare no conflict of interest.

\section{References}

1. Koza, Y. Acute kidney injury: Current concepts and new insights. J. Inj. Violence Res. 2016, 8, 58-62. [PubMed]

2. Jim, S.; Oken, D.E.; Arce, M.L.; Wilson, D.R. Glycerol-induced hemoglobinuric acute renal failure in the rat. I. Micropuncture study of the development of oliguria. J. Clin. Investig. 1966, 45, 724-735.

3. Thiel, G.; Wilson, D.R.; Arce, M.L.; Oken, D.E. Glycerol-induced hemoglobinuric acute renal failure in the rat. Nephron 1967, 4, 276-297. [CrossRef] [PubMed]

4. Ferenbach, D.A.; Bonventre, J.V. Mechanisms of maladaptive repair after AKI leading to accelerated kidney ageing and CKD. Nat. Rev. Nephrol. 2015, 11, 264-276. [CrossRef] [PubMed]

5. Basile, D.P.; Anderson, M.D.; Sutton, T.A. Pathophysiology of acute kidney injury. Compr. Physiol. 2012, 2, 1303-1353. [PubMed]

6. Shusterman, N.; Strom, B.L.; Murray, T.G.; Morrison, G.; West, S.L.; Maislin, G. Risk factors and outcome of hospital-acqusiology of acute renal failure. Am. J. Med. 1987, 83, 65-71. [CrossRef]

7. Bell, S.; Dekker, F.W.; Vadiveloo, T.; Marwick, C.; Deshmukh, H.; Donnan, P.T.; Diepen, M.V. Risk of postoperative acute kidney injury in patients undergoing orthopaedic surgery-Development and validation of a risk score and effect of acute kidney injury on survival: observational cohort study. BMJ 2015, 351, 5639-5642. [CrossRef] [PubMed]

8. Zhang, Q.; Qi, H.; Zhao, T.; Deslandes, E.; Ismaeli, N.M.; Molloy, F.; Critchley, A.T. Chemical characteristics of a polysaccharide from Porphyra capensis (Rhodophyta). Carbohydr. Res. 2005, 340, 2447-2450. [CrossRef] [PubMed]

9. Bhatia, S.; Sharma, K.; Sharma, A.; Nagpal, K.; Bera, T. Anti-inflammatory, Analgesic and Antiulcer properties of Porphyra vietnamensis. Avicenna J. Phytomed. 2015, 5, 69-77. [PubMed]

10. Isaka, S.; Cho, K.; Nakazono, S.; Abu, R.; Ueno, M.; Kim, D.; Oda, T. Antioxidant and anti-inflammatory activities of porphyran isolated from discolored nori (Porphyra yezoensis). Int. J. Biol. Macromol. 2015, 74, 68-75. [CrossRef] [PubMed]

11. Zhang, Q.; Li, N.; Zhao, T.; Qi, H.; Xu, Z.; Li, Z. Fucoidan inhibits the development of proteinuria in active Heymann nephritis. Phytother. Res. 2005, 19, 50-53. [CrossRef] [PubMed]

12. Wang, J.; Zhang, Q.; Jin, W.; Niu, X.; Zhang, H. Effects and mechanism of low molecular weight fucoidan in mitigating the peroxidative and renal damage induced by adenine. Carbohydr. Polym. 2011, 84, 417-423. [CrossRef]

13. Ustundag, S.; Sen, S.; Yalcin, O.; Ciftci, S.; Demirkan, B.; Ture, M. L-Carnitine Ameliorates Glycerol-Induced Myoglobinuric Acute Renal Failure in Rats. Ren. Fail. 2009, 31, 124-133. [CrossRef] [PubMed]

14. Singh, P.; Ricksten, S.E.; Bragadottir, G.; Redfors, B.; Nordquist, L. Renal oxygenation and hemodynamics in acute kidney injury and chronic kidney disease. Clin. Exp. Pharmacol. Physiol. 2013, 40, 138-147. [CrossRef] [PubMed]

15. Ratliff, B.B.; Abdulmahdi, W.; Pawar, R.; Wolin, M.S. Oxidant Mechanisms in Renal Injury and Disease. Antioxi. Redox Signal. 2016, 25, 119-146. [CrossRef] [PubMed]

16. Aydogdu, N.; Atmaca, G.; Yalcin, O.; Taskiran, R.; Tastekin, E.; Kaymak, K. Protective effects of 1-caenitine on myoglobinuric acute renal failure in rats. Clin. Exp. Pharmacol. Physiol. 2006, 33, 119-124. [CrossRef] [PubMed]

17. Zhao, T.; Zhang, Q.B.; Qi, H.M.; Zhang, H.; Niu, X.; Xu, Z.; Li, Z. Degradation of porphyran from Porphyra haitanensis and the antioxidant activities of the degraded porphyrans with different molecular weight. Int. J. Biol. Macromol. 2006, 38, 45-50. [CrossRef] [PubMed]

18. Zager, R.A. Rhabdomyolysis and myohemoglobinuric acute renal failure. Kidney Int. 1996, 49, $314-326$. [CrossRef] [PubMed] 
19. Park, C.H.; Tanaka, T.; Cho, E.J.; Park, J.C.; Shibahara, N.; Yokozawa, T. Glycerol-Induced Renal Damage Improved by 7-O-Galloyl-D-sedoheptulose Treatment through Attenuating Oxidative Stress. Biol. Pharm. Bull. 2012, 35, 34-41. [CrossRef] [PubMed]

20. Müller, V.; Losonczy, G.; Heemann, U.; Vannay, Á.; Fekete, A.; Reusz, G.; Tulassay, T.; Szabó, A.J. Sexual dimorphism in renal ischemia-reperfusion injury in rats: Possible role of endothelin. Kidney Int. 2002, 62, 1364-1371. [CrossRef] [PubMed]

21. Wei, Q.; Wang, M.H.; Dong, Z. Differential Gender Differences in Ischemic and Nephrotoxic Acute Renal Failure. J. Am. Soc. Nephrol. 2005, 25, 491-499. [CrossRef] [PubMed]

22. Zhang, Q.; Yu, P.; Li, Z.; Zhang, H.; Xu, Z.; Li, P. Antioxidant activities of sulfated polysaccharide fractions from Porphyra haitanesis. J. Appl. Phycol. 2003, 15, 305-310. [CrossRef]

23. Hou, Y.; Wang, J.; Simerly, T.; Jin, W.; Zhang, H.; Zhang, Q. Hydrogen peroxide released from Pyropia yezoensis induced by oligo-porphyrans: Mechanisms and effect. J. Appl. Phycol. 2015, 27, 1639-1649. [CrossRef]

24. DuBois, M.; Gilles, K.A.; Hamilton, J.K.; Rebers, P.A.; Smith, F. Colorimetric Method for Determination of Sugars and Related Substances. Anal. Chem. 1956, 28, 350-356. [CrossRef]

25. Zhang, J.; Zhang, Q.B.; Wang, J.; Shi, X.L.; Zhang, Z. Analysis of the monosaccharide composition of fucoidan by precolumn derivation HPLC. Chin. J. Oceanol. Limnol. 2009, 27, 578-582. [CrossRef]

26. Yaphe, W.; Arsenault, G.P. Improved resorcinol reagent for the determination of fructose, and of 3,6-anhydrogalactose in polysaccharides. Anal. Biochem. 1965, 13, 143-148. [CrossRef]

27. Kawai, Y.; Seno, N.; Anno, K. A modified method for chondrosulfatase assay. Anal. Biochem. 1969, 32, 314-321. [CrossRef]

28. Guo, Z.; Lei, A.; Zhang, Y.; Xu, Q.; Xue, X.; Zhang, F.; Liang, X. “Click saccharides": Novel separation materials for hydrophilic interaction liquid chromatography. Chem. Commun. 2007, 24, 2491-2493. [CrossRef] [PubMed]

(C) 2017 by the authors. Licensee MDPI, Basel, Switzerland. This article is an open access article distributed under the terms and conditions of the Creative Commons Attribution (CC BY) license (http:/ / creativecommons.org/licenses/by/4.0/). 